\title{
Design of Instruments for Navigation of Aircraft: Discussion
}

Author(s): L. F. Blandy, The Astronomer Royal, Sefton Brancker, G. H. Norman and Captain Tymms

Source: The Geographical Journal, Vol. 56, No. 5 (Nov., 1920), pp. 384-389

Published by: geographicalj

Stable URL: http://www.jstor.org/stable/1780744

Accessed: 10-06-2016 10:33 UTC

Your use of the JSTOR archive indicates your acceptance of the Terms \& Conditions of Use, available at

http://about.jstor.org/terms

JSTOR is a not-for-profit service that helps scholars, researchers, and students discover, use, and build upon a wide range of content in a trusted digital archive. We use information technology and tools to increase productivity and facilitate new forms of scholarship. For more information about JSTOR, please contact support@jstor.org.

The Royal Geographical Society (with the Institute of British Geographers), Wiley are collaborating with JSTOR to digitize, preserve and extend access to The Geographical Journal 
altitude may be of use, but again it is difficult to get the compass bearing with sufficient accuracy.

Conclusion.-The present state of aerial navigation may be briefly summed up as follows: Methods and instruments are now available which enable an aeroplane to be flown in a given direction and for a given distance through the air with an accuracy amply sufficient for present requirements. The possibility of accurate determination of the allowance to be made for the wind, however, lags far behind, and this is at present much the largest source of error. Want of space prevents a long discussion of this part of the subject, which at present has reached the stage that when the ground or the sea can be seen, the amount of the sideways drift of the aeroplane can be measured, and the true course found without great inaccuracy. The measurement of the speed of the aeroplane over the ground is subject to greater error, so that the distance travelled along any course is not always well known.

When flying above cloud or at any other time when the surface of the earth cannot be seen, allowance for wind must be made from previous measurements of the wind by meteorological means, or from two determinations of the aeroplane's position by astronomical or wireless methods. Meteorological methods of measuring the wind at all times both in and above cloud are available, and can be used when the circumstances warrant the necessary outlay. The actual "position line" can now be found by sextants to within a few miles, and position-finding by wireless appears very promising when certain difficulties are overcome.

The whole of this subject has advanced rapidly, and the initial stages may now be said to have been satisfactorily passed, though of course very much still remains to be done.

I am primarily indebted to Mr. G. L. Smith and other members of the staff of the R.A.E. for very great assistance in production of most of the illustrations and many helpful suggestions throughout the paper. The Superintendent of the Compass Department kindly supplied the photograph for Plate I, and Com. Baker the drawing for Fig. 6, while I am indebted to Major Stewart of the Instrument Section, Air Ministry, for Fig. 3. I have also to thank Major Wimperis for much information regarding the work recently done at the Air Ministry Laboratory.

Before the paper the PRESIDENT said: I have much pleasure in calling upon Mr. Gordon Dobson of the Royal Aircraft Establishment at Farnborough to give us a lecture this afternoon. He had great experience during the war upon aircraft construction, and we have looked forward to his lecture with interest.

Mr. Dobson then read the paper printed above, and a discussion followed.

Colonel L. F. BLANDy : Mr. Dobson's very clear explanation and pictures have been exceedingly interesting to me. I may say that the question of navigation over clouds and through clouds has very great importance attached 
to it by the Controller-General of Civil Aviation. The Research Department of the Air Ministry is devoting much labour and time to the solution of the problem. Mr. Dobson has told us of the difficulties to be overcome and also of the difficulty the pilot has to contend with in using his compass. Mr. Dobson also touched on direction-finding by wireless. The two last slides he showed were rather alarming pictures. The cause of the trouble of night variation has not yet been discovered ; we cannot say exactly what it is, but results are not always quite so bad as is made out by those two pictures. We used direction-finding a great deal during the war and were able to get very good results at night. The navigation of aeroplanes by means of the wireless direction-finder has come to stay. We are now training pilots to the navigation of flying boats by its means. As soon as you get out of the sight of the shore you must have some means of locating your position. I have flown from London to Paris navigating entirely by wireless direction-finder and known the whole way exactly where I was, working to a time-table. For commercial aviation to be successful financially it is absolutely necessary to get instruments which the pilot can trust : both the compass and the wireless direction-finder. The pilot is apt to trust too much to landmarks. He has to get over that if he is going to work to a time-table. I saw recently in a log of one of the men who flew on the Cairo-to-Cape flight that from Rome to Naples no attention whatever had been paid to the com. pass. That is partly due to the pilot not trusting his compass and partly due to his affection for landmark navigation. I think in the future pilots should trust more to the compass and other navigation instruments and less to landmarks.

The Astronomer Royal: I fear I cannot usefully intervene in the discussion because I have had such little experience with field instruments even on land and water, and none whatever in the air ; but if I may be allowed, I should like to say I have listened with the very greatest pleasure to $\mathrm{Mr}$. Dobson's lecture. It seemed to me he brought out extremely well the difficulties there are to overcome ; and the impression he gave me was that they seem to understand so clearly what they are driving at that one feels they are bound to conquer the difficulties and make the navigation of the air a practicable and useful thing. I have nothing more to say, except how much I have enjoyed the lecture.

General Sir Sefton Brancker: I am not a scientist, but nevertheless I am a very cordial believer in instruments. I remember Mr. Dobson's first arrival in aviation. He came to the Central Flying School as a meteorologist, but the moment he got near an aeroplane he got bitten with the dangerous microbe of aviation. He has now become one of our leading experts in aerial instruments both for piloting and navigation. I remember one of our first great difficulties at the beginning of the war was the demand for a reliable bomb sight. We soon found the impossibility of knowing the real vertical or horizontal in the air, which made the design of a bomb sight difficult. Mr. Dobson was largely responsible for developing that particular line of instrument and getting something accurate by the end of the war. It is a curious thing that the average pilot is not a believer in instruments. $\mathrm{He}$ is trained as a young man. The original pilots and the old pioneers had no instruments to go by, and they came to believe in themselves and not in the instruments. They believed in their sense of balance-hands and so on. Older men like myself, who learned to fly when they had lost that sense of balance and touch which pertains to youth, had to learn by instruments. We were rather jeered at by the young men, but personally, from the practical point of view, I am perfectly 
certain we were right, and that in future absolutely reliable instruments must be provided if we are going to make commercial aviation a success. This is more necessary than in war-time aviation. In war a man is more or less free to choose his own course, and in real thick bad weather he did not have to fly at all. In peace, the factor of greatest importance, instead of rapid manœuvring and instead of acrobatics in the air, is to run steadily to time through any weather. Your real difficulty in piloting does not arise until you get into a cloud or such thick weather that you have no horizon. Then you lose all sense of direction, and for this reason we have to develop instruments by which pilots will be able to fly through clouds with absolute confidence, knowing full well in what direction they are flying and in what position their machine is at any given moment. The compass has been wonderfully improved during and just before the war. The old-fashioned pilot used to fly into a cloud and get out of control ; then he would come back and absolutely swear the electrical disturbances had upset his compass. It was not the electrical disturbance, it was his own heavy fist. It is the same with all instruments. You have to break down the prejudice of the pilot and make him learn to believe in them before they can really be of use. Another thing which has to go hand in hand with the development of instruments is the stabilizing of the aeroplane. Before the war I think we had reached a stage in the development of inherent stability in aeroplanes to which we never attained during the war, because during the war, the war pilot-the man who had to dodge and turn in an aerial combat-was firmly convinced that a very stable machine was not easily manœuvred, and an unstable machine which he had to control was far easier to throw about and turn over and dodge the other man and so get the better position. For that reason stability was rather neglected and design has gone back in this particular respect. No matter what instruments you have, you will also have to improve the stability of aircraft. You must make them so stable that you can get into a cloud and really let the machine go uncontrolled so long as you keep the right direction, and you must be able to neglect altogether the actual maintaining of the aeroplane in the proper position. It ought to fly absolutely through any sort of weather without control, except to keep it in the right direction. There must be cures for existing defects in instruments. We must find a cure for the unreliability of the compass when flying towards the north : obviously, also, for the errors of directional wireless at night. The Government have taken the responsibility of this development on their shoulders, and so far as one can see they mean to do it well. There is one little point I would like to ask Colonel Blandy: if any progress is being made towards a small wireless directional instrument which can be used by a pilot in a small machine, without a navigator and all the equipment required at present, which will merely indicate automatically to the pilot the direction of some known wireless station? For instance, flying across the Channel you should have a wireless station at Gris $\mathrm{Nez}$ and fly on that by means of some simple wireless apparatus in the machine which would tell the pilot if he was going directly towards it, or if he was going slightly off. Directional wireless in big machines has been successfully used some time ago. I was with Colonel Blandy when we had a very interesting voyage to and from Paris in. which we used directional wireless. But I was talking of the small machine where you cannot carry a navigator and have a wireless operator and all the other things necessary for wireless navigation as it stands at present.

Squadron Leader G. H. NORMAN : When we have a good turn indicator almost any compass will do that points in the right direction when the machine 
is going straight ; but unfortunately our compasses do not even do that. It is extraordinary how carelessly compasses are fitted in the machines. I do not know much about civil machines, but in most of the Air Force ones the compass is just put in any position in which the designer thinks it will look nice. In several machines it is jammed in between guns, and is frequently $20^{\circ}$ to $30^{\circ}$ in error. The question of being able to tell whether you are turning or not by a turn indicator alters the nature of the compass we require. There was a time before we had turn indicators when the only sort of compass that was going to help us much was one with a pretty long period, and it had a lot of disadvantages attached to it. Once the compass started swinging badly, of course it took a long time to come to rest, and could not be used for some time ; but that kind of compass, heavily damped to space, was the only thing that would enable one to fly through cloud in a northerly direction. Now we want a different sort of compass that will tell you your course when you are flying straight, and we do not care much what it does when we are not flying straight. It should, however, come to rest very quickly after being stirred up. Existing aeroplane compasses are more damped to space than to the aeroplane. It is possible that a compass heavily damped to the aeroplane would do what is required.

One speaker suggested that aeroplanes should be navigated without ground observation at all. I do not agree with this, which I think comes from pushing naval analogies too far. At sea you cannot tell by looking at the coast where you are. You can only tell by definite landmarks, and then only when you are so close to the coast that you are in danger of running aground. But in clear weather you get an enormously wide view from an aeroplane, and can locate places 15 to 50 miles away. One difficulty in this connection is that the maps do not look the least like the ground. For ordinary purposes there is no object in the map looking like the ground. You cannot see the ground in plan, and the map as it stands is a very useful thing. The ground is kind enough to stay still while you correlate it with the map. In the air you have the unique advantage of actually seeing the ground in plan, but it is moving rapidly, so that you require a map which does not necessitate the translation of your observations into conventional topographical symbolism. The map we were supplied with in the Air Force is a perfectly ordinary map-the sort of map that would be rather useful to motorists. Water, which is one of the most visible things, is hardly visible, and the whole background of the map is obliterated by names of tiny and unimportant villages. At present it is almost impossible, when you have once lost. yourself, to look at your map and say where you are, because the map does not look like any sort of country you have ever seen.

General Brancker mentioned the stability of aeroplanes. The point was not mentioned, but I think that it is very important that they should be directionally stable. We want a machine that goes fairly straight when you take your feet off the rudder bar. It will never go absolutely straight ; but we have a number of machines which are not directionally stable at all. If you let them go, they start turning with increasing velocity until you get into a spin. There are some machines which you can hardly call directionally stable even when the rudder is held stationary. I am perfectly sure nobody can keep a Bristol fighter straight without continually moving the rudder. These machines are extremely difficult to take sextant observations from, using an artificial horizon. Practically all our machines are stable laterally, but many of them are not stable directionally, though there are such machines: 
you may have to keep your foot on the rudder bar, but when going straight there is practically nothing to do.

I never had any experience of taking sextant observations at sea, using artificial horizon, and I was told by naval officers during the war that it is practically impossible. I imagine it is much more difficult at sea than in the air, and I think people who have not flown have not realized how absolutely still an aeroplane can be. You can feel whether there are any bumps, if you want to find out whether you can use an artificial horizon. Apart from bumps, in some experiments I did some little time ago I found that four consistent observations always gave very fair accuracy. Where the extreme observations did not differ by more than twenty minutes of arc, we never had a greater error of more than twelve minutes in the mean, and generally speaking eight minutes. If there were any bumps, the consecutive observations were degrees out. You have one great score over ships in navigation by stars and sun : they are so very much more visible. A sextant was mentioned for using the cloud horizon. Personally, I think the artificial horizon is the only possible thing to use. There is no means of knowing, when you take a cloud horizon, whether it is right or not, and that seems to me to knock it out completely.

Captain Tymms : On a recent flight I used some of the instruments which Mr. Dobson has shown us. Before saying anything about them, however, I should like to support Major Norman's statement as to artificial horizons. This question of cloud horizons is very difficult, as one cannot rely on definite conditions. From my own experience and what I have seen of others', I think that the future development of the sextant for use in the air will be in the direction of the artificial horizon. Returning to the consideration of particular instruments, I took a good many observations with the R.A.E. sextant, and the average error was considerably less than ten minutes of arc, while the variation in individual readings was not anything like as much as that laid down as a safe limit by Major Norman. The accelerations of the bubble in the air were very small indeed. When the pilot was trying to fly the machine straight-and I must say I had a very good pilot-there was practically no movement of the bubble. The results obtained show that such movement is almost negligible. I have also used the Baker sextant and the nautical sextant in the air. The results are subject to error in each case from the cause already mentioned. With the nautical sextant there is uncertainty in the calculation of your height above the horizon, while with the Baker sextant you may sometimes get a perfect cloud horizon where back and front horizons are level, but you cannot rely on it. In the air, if you can get your position line within, say, 5 to Io miles, that is sufficient, and if you can produce an artificial horizon sextant which will do this, the operation is considerably simplified. That is what I think the R.A.E. sextant will do.

As to the general question of navigation: if you can see where you are going, that is sufficient, without steering by compass. There are certain parts of the world where you can see your course very plainly in front of you for 40 or 50 miles. Going down the coast of Greece to Athens is an example. In such a case it is not necessary to work out a course. It is rather a waste of time: I should compare it with trying to bring a ship into harbour by means of the sextant, and neglecting the buoys. There are certain types of country, however, and England is one, where pilotage is insufficient, and you must use navigation. You must work out and steer a course, because visibility here is so bad.

The PRESIDENT: We must all have been impressed with the tremendous 
difficulties airmen have in finding their direction, at the rate at which they are travelling, and with the extraordinary skill by which these great difficulties have been overcome. There seems to be a difference of opinion amongst airmen whether they should trust to themselves or to instruments, but it is quite certain that instruments will have to be invented for navigation in the air entirely by instruments. General Brancker pointed out that for civil aviation services such as that from Paris to London, or London to Delhi, must be kept up quite irrespective of the weather, and instrument inventors must have as their ideal the provision of our Air Services with instruments which will fulfil that purpose. I am sure you would wish me to give, on your behalf, a most hearty vote of thanks to Mr. Dobson for the paper this evening, and congratulate him on the great services he rendered during the war by his inventive capacity.

\section{THE DINKA COUNTRY EAST OF THE BAHR-EL- GEBEL}

\section{Major J. Stevenson-Hamilton, late Inspector, Bor}

T HE country, especially near the river, has been partially surveyed with greater or less accuracy by various officers of the Egyptian Army and officials of the Sudan Government in the course of administration or during the occurrence of the reprisal expeditions against predatory tribes, which have been necessary from time to time. Excepting, however, for the river surveys and that conducted when the Khartoum-Rejaf telegraph line was constructed, most of these mappings have been carried out with the aid of the pocket compass and dead reckoning, which, in a country so devoid of landmarks as this, cannot naturally be relied on for the best results. The eastern portion has never till recently been surveyed or even explored at all. In I904 Captain Liddell, R.E., made an expedition from Taufikia on the Sobat to the Twi country, and the notes made by him, together with map, were embodied in the Fournal for December of that year. Since then little has altered in either country or people, except that Government influence has slowly extended from the river into the hinterland.

The Dinka, or more correctly the Jeng, ${ }^{*}$ race, despite the curtailment of much of its territory and the absorption or extinction of many of its tribes by hostile neighbours during the last half-century, still extends over a large portion of the flat country on either side of the Bahr-el-Gebel and Sobat rivers; but the country lying to the east of the former stream and south of lat. $8^{\circ} \mathrm{N}$. contains only four tribes, whose country I shall attempt to describe.

These tribes are, from north to south, named respectively, (G)Ol (or $\ddot{\mathrm{G}}$ ol), Nyareweng, Twi, and Bor, and each of them is split up into a number of separate and independent clans, each under its own chief.

* The people call themselves $\mathcal{F}$ eng. Dinka may be an Arabic corruption of Deng Kurs, a district south of the Sobat. 